v. 01, n. 02 : pp. $01-17,2005$ ISSN $1808-0448$

\title{
A EVOLUÇÃO DAS CADEIAS DE SUPRIMENTOS E A CONTRIBUIÇÃO DO SISTEMA ERP
}

\section{THE EVOLUTION OF THE SUPLLY CHAINS AND THE CONTRIBUTION OF THE SYSTEM ERP}

\author{
Claudio Aparecido Pradella ${ }^{1}$; Weider Robeson Silva ${ }^{2}$ \\ ${ }^{1}$ UNICAMP; pradella@kbonet.com.br \\ ${ }^{2}$ UNICAMP; weidersilva@aol.com
}

Recebido para publicação em: 03/02/2005

Aceito para publicação em: 20/06/2005

\section{RESUMO}

Este texto apresenta alguns conceitos e tendências sobre ERP e SCM, com a ilustração de um caso real, em uma empresa de elevadores, e a conclusão com a sugestão de um possível desenvolvimento, em um futuro bem próximo, nas novas necessidades especificas do sistema ERP para atendimento às Cadeias de Suprimento.

Palavras-chave: Cadeia de Suprimento, Sistemas Cooperativos, ERP.

\section{Introdução}

As Cadeias de Suprimentos estão sempre em constante processo de mudança para continuarem alinhadas com as novas economias de mercado. $\mathrm{O}$ mundo globalizado exige velocidade e precisão nos negócios, requerendo um esforço cada vez maior dos elementos de uma cadeia de suprimentos para atender as necessidades, cada vez mais, personalizadas dos consumidores e suas exigências por qualidade, preços e prazos menores.

A informação, passa a ter papel fundamental nesta nova economia. As necessidades dos clientes têm que ser transmitidas cada vez com mais velocidade e exatidão para as empresas que participam do processo produtivo do produto. O ERP que teve sua grande parcela de contribuição no sucesso das empresas na década de 90, agora começa a sofrer de limitações e uma nova forma de sistema de informação vem surgindo. Observa-se que a internet passa a ser o meio de transmissão mais eficaz e de fácil acesso para as empresas, oferecendo maior sucesso de integração para as novas tendências das cadeias de suprimentos.

Neste estudo, são apresentadas as tendências das cadeias de suprimentos e os pontos onde o ERP pode contribuir, finalizando com a apresentação de um estudo de caso. O caso estudado refere-se à uma empresa fabricante de elevadores que enfrenta problemas de prazo e altos custos 
decorrentes da pobreza das informações fornecida pela equipe de vendas. Com a implementação de uma solução que integra o sistema de ERP a uma ferramenta web-enabled que possibilita acesso a todo o Brasil e América Latina, isto propicia uma padronização da informação e um aumento da visibilidade do produto que deve ser fabricado a toda a cadeia com considerável redução de prazo de disponibilização da informação.

\section{Cadeia de suprimentos}

Segundo Akkermans et al (2003), a cadeia de suprimentos é como uma rede, constituída de fornecedores, fabricantes, distribuidores, revendedores e consumidores, como ilustrado na Figura 1. Em nível operacional, esta rede suporta três tipos de fluxos os quais requerem um cuidadoso planejamento e uma coordenação muito forte:

- Fluxo de material: representa o fluxo físico de produtos vindo dos fornecedores para os consumidores, bem como o fluxo reverso de retorno de produtos provenientes de serviços de reparo, garantia e reciclagem.

- Fluxo de informações: este representa a transmissão do pedido e o rastreamento do mesmo, o qual coordena o fluxo físico dos produtos.

- Fluxos financeiros: neste, são representados os termos de crédito, cronogramas de pagamento e arranjos de propriedade e consignação.

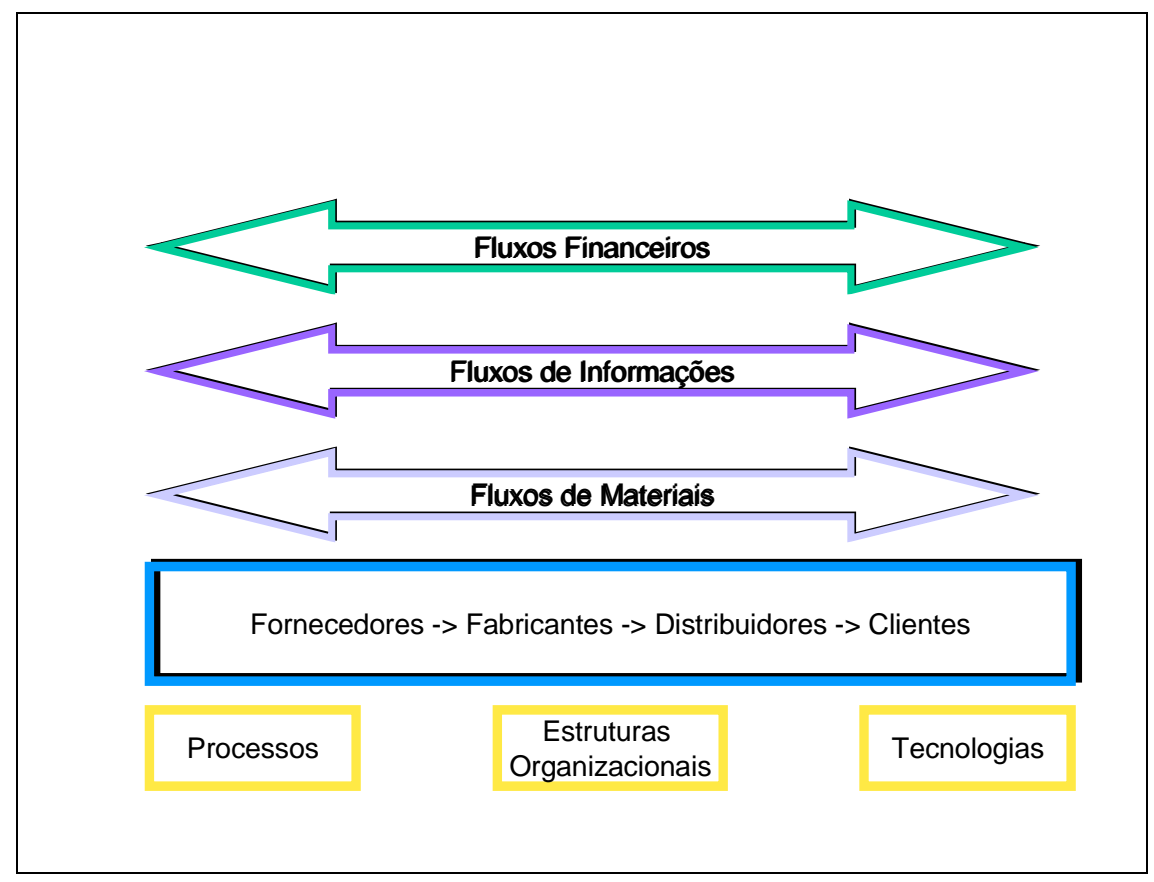

Figura 1 - Modelo integrado da cadeia de suprimentos (Akkermans, 2003)

Esta rede tem sua operação suportada por três pilares: 
- Processos: estão embutidos nas capacidades da empresa como: logística, desenvolvimento de novos produtos e gestão do conhecimento.

- Estruturas organizacionais: representam uma grande faixa de relacionamentos nos sentidos horizontais e verticais da empresa e da cadeia de suprimentos. Engloba assuntos como gestão do capital humano, recompensas, medidas de desempenho e formas de gestão da empresa.

- Tecnologias: incluem dois aspectos, processos e tecnologia da informação.

As cadeias de suprimentos desempenham dois papéis principais (Fisher, 1997): o primeiro, a função física de transformação, armazenagem e transporte. $O$ segundo, a mediação com o mercado, função que tenta conciliar a demanda com a oferta. Enquanto a função física tem sido exaustivamente estudada dentro das literaturas voltadas ao controle da produção e gestão de estoques com uma visão de minimização de custos, a função de mediação com o mercado começou recentemente a ser estudada (Akkermans, H., et al, 2003).

Esta forma de interpretação mais voltada para o cliente é representada na Figura 2, onde claramente são apresentados os componentes constituintes da função de mediação com o mercado. Nesta estrutura destacam-se dois componentes: o projeto da cadeia de suprimentos e a coordenação desta cadeia, o que podemos entender por governança da cadeia. $\mathrm{O}$ projeto da cadeia de suprimentos refere-se a especificação das áreas onde encontram-se os clientes, seleção das empresas de manufatura e distribuição, localização das plantas e suas famílias de produtos, como também à priorização de capacidades a serem desenvolvidas e retidas através de parcerias com os elementos constituintes da cadeia. Esta visão deve acompanhar a dinâmica do mercado, que requer perspectivas diferentes para a cadeia de suprimentos, quais sejam:

- Mapa organizacional: mostra todos os elementos constituintes da cadeia de suprimentos e ilustra as atividades que agregam valor, desempenhadas por cada organização.

- $\quad$ Foco em tecnologia: traça as linhas de dependência na transferência de informação entre os participantes da cadeia.

- $\quad$ Foco em capacidade: objetiva identificar as capacidades chaves dos processos de negócio, mostrando os valores existentes e os desejados para o alcance das metas de demanda da cadeia. 


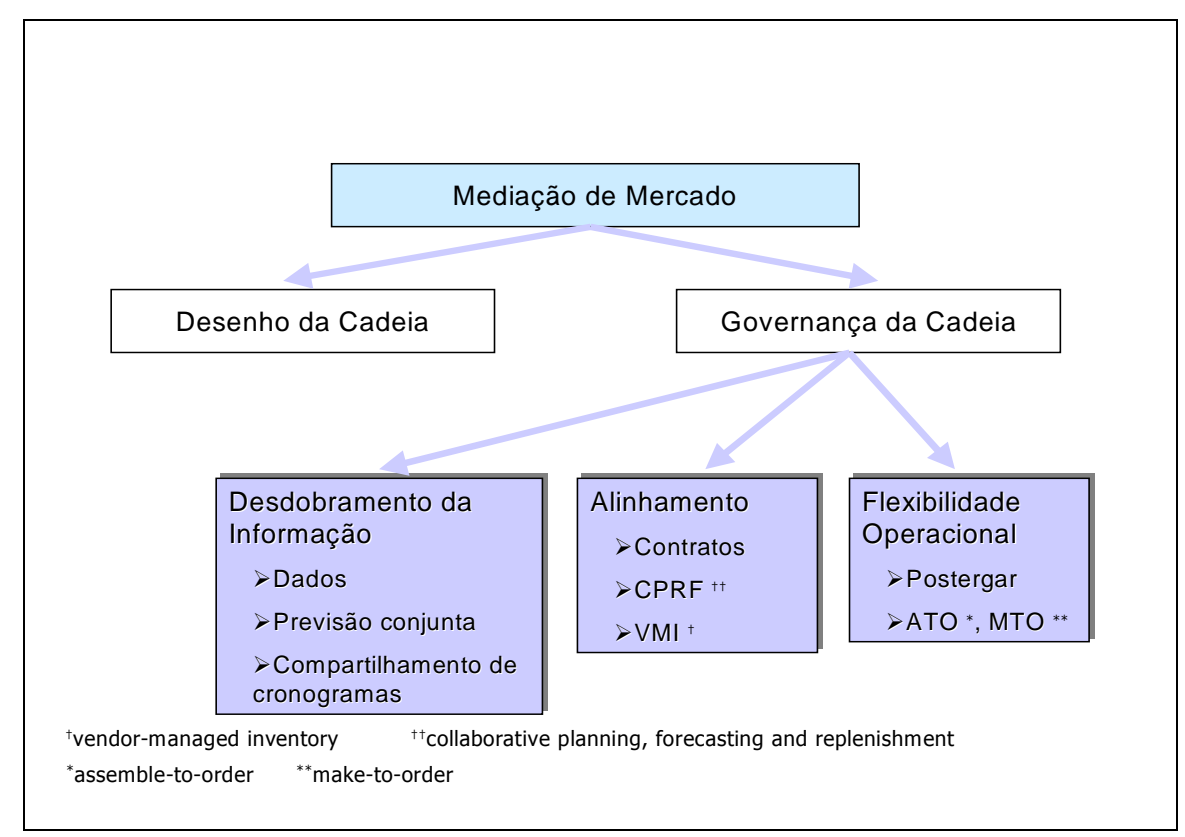

Figura 2 - Modelo da função de mediação com o mercado (Akkermans, 2003)

Estratégias efetivas para as cadeias de suprimento combinam uma gama de soluções operacionais tais como: make-to-order, vendor managed inventory, e tomada de decisões conjuntas através do desdobramento da informação (ex: collaborative planning, forecasting and replenishment). Estas estratégias podem levar a um novo tipo de estrutura organizacional, como exemplo: estruturas voltadas a processos ou outsourcing.

\subsection{Tendências para a cadeia de suprimentos}

Conforme estudo realizado por Akkermans, et al (2003) junto a 23 empresas alemãs, com o objetivo de identificar as tendências da cadeia de suprimentos e o papel do ERP, constatou-se: 1) maior integração de atividades entre fornecedores e clientes, através de toda a cadeia de suprimentos; 2) processos e informações mais padronizadas; 3) constantes mudanças nas necessidades da SCM, requerendo maior flexibilidade dos sistemas de informação; 4) crescimento da personalização dos produtos e serviços, levando a um aumento da diversidade de opções existentes, e ao mesmo tempo exigindo reduções de custos e 5) cadeias de suprimentos compostas por várias empresas independentes.

As cinco tendências verificadas foram agrupadas para discussão da seguinte forma: Os assuntos relacionados à integração de atividades entre fornecedores e clientes e a composição das cadeias por uma série de empresas independentes, serão discutidas através das formas de gestão de cadeias de suprimento e a importância do relacionamento entre as empresas constituintes da SCM. 


\subsubsection{Formas de gestão para a SCM}

A proposta de enfoques para gestão de (Carvalho, 2001), engloba duas versões, sendo estas: gestão federativa e gestão centralizada.

Baseando-se na colaboração entre entidades independentes, o planejamento federativo, inicia-se com alinhamento de objetivos e estende-se por um processo interativo de discussão dos objetivos sobre custo e escolhas a respeito do nível de serviço, onde podem assim definir um acordo sobre os níveis de desempenho, incentivos, regras e limitações. As limitações definem as políticas e os alvos que governam o fluxo de informações entre as organizações, permitindo às cadeias de suprimentos monitorar as mudanças no mercado, mas não visualiza restrições decorrentes da demanda.

O alinhamento dos objetivos em torno do nível de serviço desejado é um dos principais fatores para o funcionamento da cadeia. Também serão compartilhados neste modelo, a demanda projetada e a miscelânea de produtos, bem como o potencial de incerteza com relação à demanda. Como exemplo de nível de serviço desejado tem-se: a) prazo de atendimento de pedidos; b) taxa de atendimento de pedidos; c) preço, etc.

Definição de Planejamento Federativo: baseada na visão federalista de colaboração entre entidades independentes - é um processo de colaboração estratégica que começa com o alinhamento dos objetivos de negócios. Por um processo de discussões interativas e objetivas sobre custo e intercâmbio de serviços, os parceiros da cadeia de suprimentos podem entender as restrições críticas e os determinantes do custo da rede de suprimentos e chegar a acordos sobre níveis de desempenho, incentivos, regras e limites conforme ilustra a Figura 3.

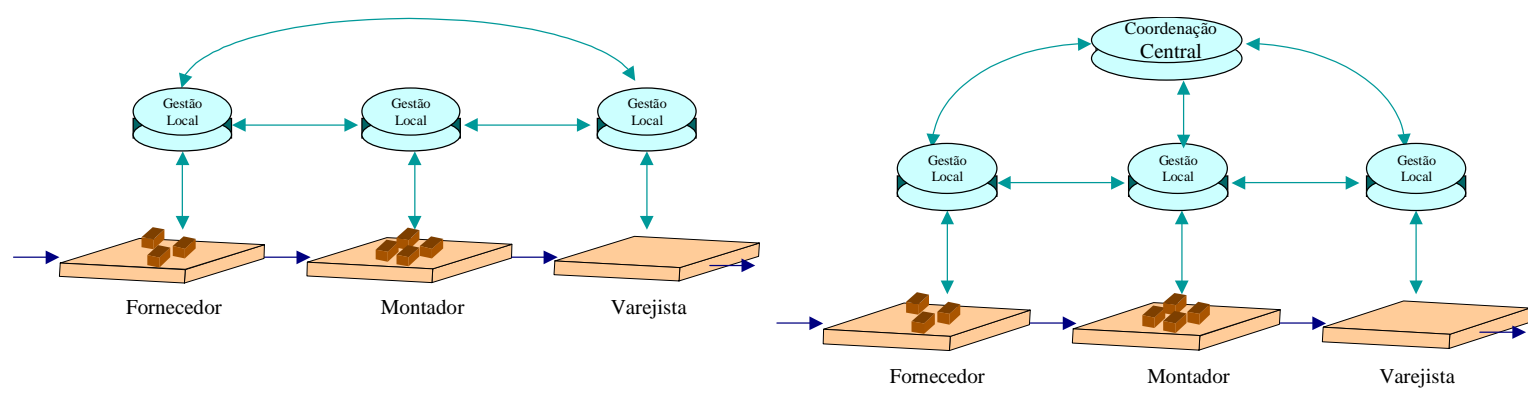

(a)

(b)

Figura 3 - Modelos de gestão: a) Federativa; b) cooperativa (Carvalho, M. F., 2001) 
São considerados três pontos chave para o planejamento federativo, sendo o primeiro: não tentar ditar "soluções" para a cadeia de suprimentos do empreendimento estendido, mas confiar nas negociações entre os parceiros da rede de suprimentos para defini-la e gerenciá-la. Em segundo lugar, a colaboração é alcançada pelo alinhamento de objetivos de negócios, não pela troca de dados detalhados. Finalmente a terceira, a abordagem federativa não tenta gerar uma solução para um determinado instante de tempo, mas é um processo interativo projetado para mudar com as variações das condições do mercado.

O modelo de gestão centralizada apresentada por (Carvalho, 2001) reconhece que a condição essencial para integração está na coordenação de ações, através de um fluxo livre de informação e conhecimento, entre os parceiros. Isto significa democratização e disseminação das informações e decisões pela rede em todas as direções, independentemente do tamanho da empresa ou de sua posição, sempre em busca de ações e decisões que conduzam a um melhor desempenho para todo o grupo.

A coordenação é o gerenciamento das dependências entre as atividades realizadas pelos membros da SCM (Rice, J. B, 2002). Surge então a questão: Quais são as atividades que necessitam de coordenação numa SCM multi nível? Devido às complexidades da SCM, que é formada por inúmeros parceiros, o caminho para a coordenação eficiente é identificar os componentes estratégicos da SCM, e junto com eles criar a rede colaborativa com níveis distintos de coordenação e decisão.

O primeiro nível de coordenação refere-se ao fluxo de informações que deve ocorrer através de modernos sistemas de informação capazes de fornecer visibilidade para todos os elementos da cadeia. O segundo nível é a coordenação dos processos logísticos e operações através da SCM. Finalmente, o terceiro nível suporta decisões que alteram o desempenho e funcionamento de toda a SCM da empresa. As decisões neste nível são relativas a escolhas que devem equilibrar a relação financeira (investimentos, redução de custos, benefícios intangíveis) com os riscos associados, para toda a cadeia onde a empresa se encontra. 


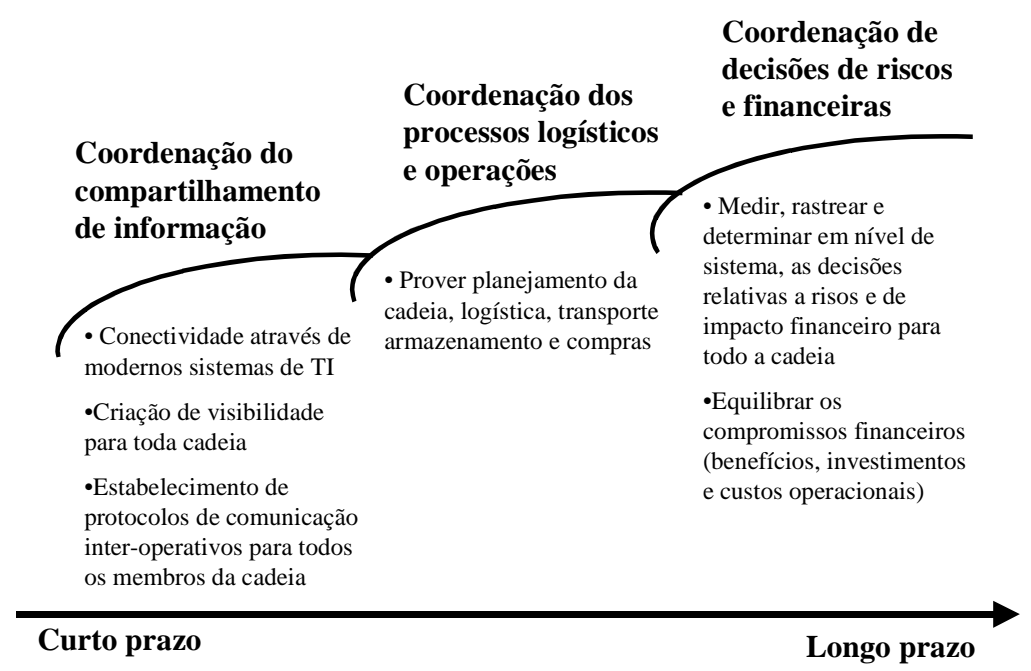

Figura 4 - Os tres níveis de coordenação para a SCM (Rice, J. B., 2002)

Coordenação e compartilhamento de informações: neste nível o usuário da informação é totalmente dependente do emissor de informações, isto indica a necessidade de um emissor altamente confiável e que possa disponibilizar a informação em tempo real para os usuários. Com o advento dos sistemas de ERP voltados para aplicações em cadeias de suprimento, é possível a conectividade entre todas as empresas participantes da cadeia com a fonte geradora de informações. Propicia visibilidade para toda a cadeia melhorando o desempenho da mesma.

Coordenação dos processos logísticos e operações: aplicando a coordenação de processos logísticos e operações de fluxos de materiais, a natureza das dependências entre produtor e consumidor na transferência de bens, passa a ser subordinada ao fornecedor que irá transferir os bens para o montador e posteriormente para o consumidor. Observa-se uma inversão na ordem da dependência entre os participantes da cadeia, ao comparar-se a Coordenação da Informação. Isto sugere que os aspectos importantes na estrutura destes processos devem ser o sequenciamento, rastreamento de fluxos de materiais, gerenciamento de estoques e usos de técnicas como o JIT.

Coordenação de decisões de risco e financeiras: neste plano a coordenação refere-se ao compartilhamento de recursos de alguma forma. Freqüentemente neste nível as decisões são para os orçamentos de investimentos para melhoria da cadeia, formas de tomar decisões gerenciais e regras de resolução de problemas. Observa-se que o impacto ocorre a longo prazo na gestão da cadeia.

O alinhamento desta hierarquia de decisões é apresentado na Figura 4, onde a coordenação central é a responsável pelo tratamento, controle e distribuição da informação, no sentido de aumentar a competitividade da cadeia. Esta disseminação da informação pode ser realizada por modernos sistemas de tecnologia da informação. As empresas, podem trocar livremente dados e comentários negociando entre elas e tomando decisões do dia-a-dia operacional 
Realizando ações com relação a problemas propostos acerca das decisões tomadas pelo nível cooperativo ou mesmo acerca de perturbações que venham a ocorrer em seus sistemas que não comprometam significativamente as metas centralizadas. Então, as empresas parceiras vizinhas se relacionam de forma federativa guiadas pelas metas estabelecidas pelo nível de coordenação da cadeia.

\subsubsection{A importância de construir relacionamentos}

Gerenciamento da Cadeia de Suprimentos é ter tudo a respeito de software e sistemas de tecnologia da informação, bastando ter a melhor tecnologia existente, sentar-se atrás de seu computador e rodar com cuidado seus programas salvando as informações para ter tudo resolvido. Certo? Não é exatamente assim. Em um painel de debates, realizado por (Kirby, 2003) para a Harvard Business Review, onde participaram pessoas especialistas na área de Cadeia de Suprimentos, foram explorados outros aspectos da SCM, como obstáculos e oportunidades, talentos, o papel dos executivos e as últimas tecnologias. Em uma abordagem sobre o foco atual da SCM, o consenso foi que atualmente a maior preocupação está na redução de custos, o que anteriormente era focado na velocidade de resposta para a reposição. As estratégias hoje também são refeitas baseando-se em informações em tempo real, parceiros, tendências e etc. Hoje, o principal para os negócios é cortar custos para sobreviver, porém, deve-se inovar para prosperar (Lynch, R. P., 2003).

Nesta linha de pensamento, deve-se buscar a harmonização entre os sistemas de informação e troca de dados entre empresas, com estratégias e acordos de fornecimento onde existe a função "ganha-ganha". Para conseguir atingir tais objetivos é necessário a criação de uma rede de relacionamento efetiva e eficaz entre as empresas, através de seus líderes.Segundo (Kirby, 2003) numa relação onde se tem apenas um parceiro para uma única tecnologia, o que fazer quando ele diz a você que estará fechando as portas na próxima semana? Como é possível vislumbrar este tipo de problema com antecedência e verificar a saúde de fornecedores, para antecipar desastres como este? Confiança é essencial para o relacionamento, claro, porém antes de confiança deve existir um contrato inteligente (Gopal, C., 2003). Atualmente, as melhores companhias estão iniciando uma triagem de sua cadeia de suprimentos. Em outras palavras, vão separar vendedores de "commodities", de fornecedores preferenciais com os quais possuem um bom relacionamento e podem criar alianças estratégicas para a cadeia de suprimentos. Eles manejam o fornecimento com base em diferentes elementos e caminhos, usando diferentes métricas, processos, pessoas e diferentes mentalidades. 
Assim, pode-se inferir que Talento é uma das chaves do sucesso. Mas o que pensar sobre a tecnologia? Ela não é tão fundamental como muitas pessoas acreditam? Há duas correntes de pensamento.Uma delas acredita que escolhendo o software correto as empresas podem se ver livre das pessoas. É muito simples. A outra corrente é que, a tecnologia da informação e outras tecnologias são capacitadoras e podem ser tremendas ferramentas quando você possui a pessoa certa no lugar certo (Burt, D.N., 2003).

\section{Impacto do ERP sobre as tendências da SCM}

\subsection{Conceito de ERP}

Existem diferentes formas de definir-se um sistema de ERP, podendo ser de uma perspectiva de negócio, técnica ou funcional. Para uma visão mais completa do sistema, este será descrito sob três perspectivas.

Perspectiva do negócio: Uma forma de descrever o ERP é como uma combinação de processos de negócio e tecnologia da informação. Segundo J.D. Edwards, um fabricante de ERP possui a seguinte definição:

"O ERP funciona como um guarda-chuvas para um sistema de negócio integrado, condensando todos os processos de negócio de uma empresa, indo desde as atividades relacionadas a produção até os processos financeiros. Funciona como uma cola que une as informações da empresa numa base comum. Propiciando uma integração entre as coorporações que transcedem até as questões geográficas e as complexidades das várias redes de informações entre as diversas áreas funcionais de uma empresa."

A perspectiva técnica do ERP, pode ser encarada como sendo uma extensão lógica dos sistemas de MRP da década de 70 e dos sistemas de MRP II da década de 80. O ERP conseguiu eliminar uma série de legacy systems usados na operação das empresas, onde estes eram programas de computador independentes uns dos outros e muitas vezes instalados em hardwares dos mais diversos, criando assim uma infraestrutura complexa para manutenção e gestão. A solução de criar um programa de computador com vários módulos baseados na mesma plataforma foi uma grande solução técnica de integração tanto para os programas, quanto para a infraestrutura de tecnologia de informação. Isto foi um dos grandes propulsores do sucesso do ERP nas empresas.

Do ponto de vista funcional, o ERP tem como escopo primário suportar a gestão e a administração do desdobramento dos recursos dentro de uma mesma organização. Tais recursos podem ser: materiais, capacidade de produção, recursos humanos e etc.

Conforme Akkermans, et al (2003), implementar um sistema de ERP numa empresa é uma tarefa formidável, o que vem rendendo uma série de estudos acadêmicos a respeito dos desafios de 
um projeto de implementação de ERP. Entretanto, muito pouco estudo existe sobre o impacto do ERP no desempenho de uma empresa após sua implementação.

\subsection{Personalização}

A demanda por configuradores de produto surgiu da necessidade de proliferação de produtos surgida nos últimos 10 anos. Num mercado altamente competitivo, uma empresa que consegue fabricar bens de acordo com as necessidades específicas dos clientes, pode cobrar um preço superior, além de ser vista como uma empresa capaz de atender de forma satisfatória seus clientes. Atualmente a variedade de produtos não é mais restrita somente aos complexos e caros bens de capital, podemos testemunhar um alto nível de variedade de produtos que no passado era inimaginável. Um exemplo muito próximo é a escolha de um automóvel, onde o cliente expressa sua preferência por opcionais quando faz o pedido de compra. Similar ocorre com computadores, roupas e diversos serviços que são oferecidos numa enorme gama de variações.

Devido à complexidade dos novos produtos decorrente de sua variabilidade, as empresas encontram dificuldades em atingir eficiência operacional. A redução dos volumes dos lotes de produção, o aumento da carga de trabalho ligada ao desenvolvimento de numerosas variações de novos produtos, a proliferação de inventários de produtos acabados e semi-acabados, são somente algumas das dificuldades enfrentadas pelas empresas.

Muitas soluções têm sido empregadas como objetivo de aumentar a eficiência operacional. Um exemplo é a introdução do conceito de modularidade, o que aumenta a flexibilidade e melhora o controle de produção. Assim determinar a quantidade de variantes é muito importante, pois isto determinará o atendimento das necessidades dos clientes.

Mas, infelizmente, mesmo a empresa tendo atingido este estado da arte na produção de uma alta variedade de produtos, o mesmo não ocorre nos processos de geração de cotação e de pedido de fabricação.

Por esta razão é necessário fornecer ao cliente mais informações, para que ele tenha capacidade de fazer uma opção racional dentre várias alternativas oferecidas pela empresa, ou criar um ambiente que tenha sistemas inteligentes para direcionar o cliente para a escolha correta. Quanto ao lado da empresa, torna-se mais difícil armazenar e processar grandes volumes de informação descrevendo os pedidos dos clientes. Isto cria a necessidade de uma ferramenta capaz de relacionar as ordens com os pedidos dos clientes. Os pedidos dos clientes são descritos numa linguagem comercial requerendo uma tradução para ser criada uma documentação de produto apropriada, que irá gerar a ordem de fabricação. As empresas que fabricam produtos altamente complexos desenvolvem seus próprios programas, que são comumente chamados de Configuradores, que 
garantem a congruência entre a especificação do cliente e a geração da ordem de fabricação. No entanto, nos últimos anos muitas empresas de Tecnologia da Informação estão disponibilizando sistemas de ERP [Enterprise Resource Planning] com pacotes adicionais de configuradores de produtos, como é o caso do SAP, Microsiga, Baan, J. D. Edwards, etc. Mas ocorre que estes pacotes não são desenhados para o processo da empresa em particular e sim para um processo chamado de genérico. Na implementação de um configurador de produtos muitos problemas podem ocorrer caso o processo da empresa não seja desenhado no sistema.

\section{A experiência de uma empresa no uso do ERP para melhoria da SCM}

O estudo de caso apresentado refere-se a uma empresa fabricante de elevadores. $\mathrm{O}$ problema estudado foi o alto prazo e altos custos do processo de venda de produtos para modernização de elevadores. O prazo para entrega de um produto era de 6 meses e com altos custos, decorrentes da falta de visibilidade para os participantes da cadeia de suprimento. O projeto de melhoria do sistema consistiu na introdução de um sistema informatizado web-enabled conectado ao sistema de ERP (SAP R/3) da empresa. Neste sistema os clientes localizados em todo Brasil, passaram a ter acesso direto à criação de um orçamento e fechamento da proposta de compra de produtos para modernização de elevadores. Com isto a cadeia de suprimentos passou a ter visibilidade sobre o tipo de produto vendido podendo programar-se mais cedo para atendimento ao pedido, comparado com o sistema anterior.

Os produtos de modernização de elevadores são altamente variáveis, requerendo um sistema que permita a configuração conforme a aplicação do produto. Exemplificando: os edifícios possuem alturas diversas, bem como seus elevadores possuem capacidade de transporte de passageiros variável, podendo ser 3 passageiros até 26 passageiros por elevador, além de várias velocidades de viagem $(1 \mathrm{~m} / \mathrm{s}$ até $8 \mathrm{~m} / \mathrm{s})$ e vários outros parâmetros. Isto faz com que os produtos necessitem ser configurado caso a caso.

Assim, os fornecedores não podem fabricar para estoque, porque dependem de receber a informação a respeito das características do produto vendido para poderem comprar material e fabricarem. Como o processo de venda ocorria de forma manual, a visibilidade dos fornecedores era limitada acarretando em prazos de entrega muito dilatados, além da ocorrência de erros de especificação do produto que geravam altos custos. 


\subsection{Definindo o Problema}

Foi realizado um estudo pelo departamento de Processos de Negócio e levantados os processos Centrais e de Suporte para modernização. São considerados processos centrais, aquelas atividades essenciais para a entrega do produto, os processos de suporte fornecem recursos ou capacidades-chave que permitem o desenvolvimento dos processos centrais. Os processos centrais considerados foram os seguintes:

Prospecção: é o processo de atrair e manter os clientes na organização. Procura identificar as necessidades dos clientes e fomentar a venda. A entrega deste processo é uma solicitação de orçamento.

Orçamento: processo que determina a configuração do produto, seus custos e realiza a atividade de avaliação financeira onde é determinado o preço de venda e prazo de entrega.

Proposta e assinatura do contrato: são atividades realizadas pelo vendedor, baseia-se na negociação junto ao cliente das condições oferecidas no orçamento e da conclusão do negócio frente à assinatura do cliente na proposta comercial.

Criação da ordem de venda: é o processo de confirmação da venda no sistema de ERP da empresa (SAP/R3). Em muitos casos é necessária a complementação de algumas informações que não são relevantes para o custo durante a fase de proposta, mas necessárias para a fabricação do produto, como exemplo a cor de um produto.

Networks: cada venda é tratada como um projeto e possui uma rede de atividades, no entanto para cada família de produto esta rede é padronizada. É necessária que seja determinada na rede a data de entrega do produto, assim a empresa organiza-se para atender o prazo contratado pelo cliente.

Engenharia: realiza o processo de desenhar e especificar o produto em detalhes, além de determinar a lista técnica de material necessária para a fabricação.

Fabricação e logística: fabricação do produto de acordo com a Ordem de Venda de Manufatura e realiza a remessa do produto para a região que realizará a montagem do produto no edifício.

Recebimento em campo e montagem: o processo de receber o material no escritório da região, preparação do prédio para a realização da montagem e a montagem do equipamento.

Entrega ao cliente: realizada a montagem e testes, é apresentado ao cliente o equipamento modernizado e solicita-se o aceite ou reprova da entrega do equipamento. Mediante a aceitação pelo cliente, é feita a passagem do equipamento para o grupo responsável pela conservação/manutenção que deverá também fazer o aceite ou reprova da modernização.

Medições pós-venda: dois meses após a entrega do equipamento é feito uma pesquisa de satisfação do cliente e o resultado contabilizado, nos indicadores da empresa. 
A identificação do problema iniciou-se na análise do índice de satisfação dos clientes. Das pesquisas analisadas foi verificado que cerca de $70 \%$ da insatisfação dos clientes é decorrente do problema de atraso na entrega da modernização. As razões que acarretam o atraso são várias, desde problemas de erro no escopo de venda, levando a especificação de um produto que não irá atender a aplicação do cliente até problemas na fábrica como falta de capacidade e problemas de fornecimento.Nestes processos o problema é a falta de padronização na forma e no tipo de atividades realizadas. Cada região possui sua maneira de trabalho e atribuem as tarefas para pessoas com os mais variados perfis e funções na empresa.

Como resultado do Pré-Estudo, ficou a necessidade de rever os processos desde a fase do orçamento até a criação das networks. Com isto, os objetivos são: aumentar a satisfação dos clientes, melhorar a estimativa de custo durante a fase de orçamentos, reduzir o prazo de entrega dos produtos, orçamentos e os erros de especificação.

Durante a identificação de soluções possíveis as propostas formam: a implementação de um sistema informatizado que realize a configuração e determina preços para orçamentos ou utilizar um grupo específico de trabalho, composto de especialistas que realize a tarefa manualmente e retransmita as informações para cada região que realizou o pedido.

\subsection{Encontrando a solução}

A meta do projeto foi tornar o processo de venda e pós-venda robusto reduzindo as possibilidades de especificação errônea dos produtos, tornar mais veloz o processo de orçamentação através da descentralização, tornar a atividade de especificação e geração de networks automática.

O projeto foi realizado num prazo de 12 meses, maximizando o uso dos recursos internos da empresa e reduzindo o uso de consultorias. A entrega do projeto foi um sistema de informação onde os usuários podem configurar os produtos, obter preços e informar a cadeia de suprimentos a data de entrega e o produto a ser entregue.

O projeto consistiu na criação de um sistema para integração dos processos e eliminação de atividades que não agregam valor, realizadas pelos colaboradores. O sistema é baseado no ERP da empresa e uma interface com o usuário feita em Java acessível através de um navegador de internet. 


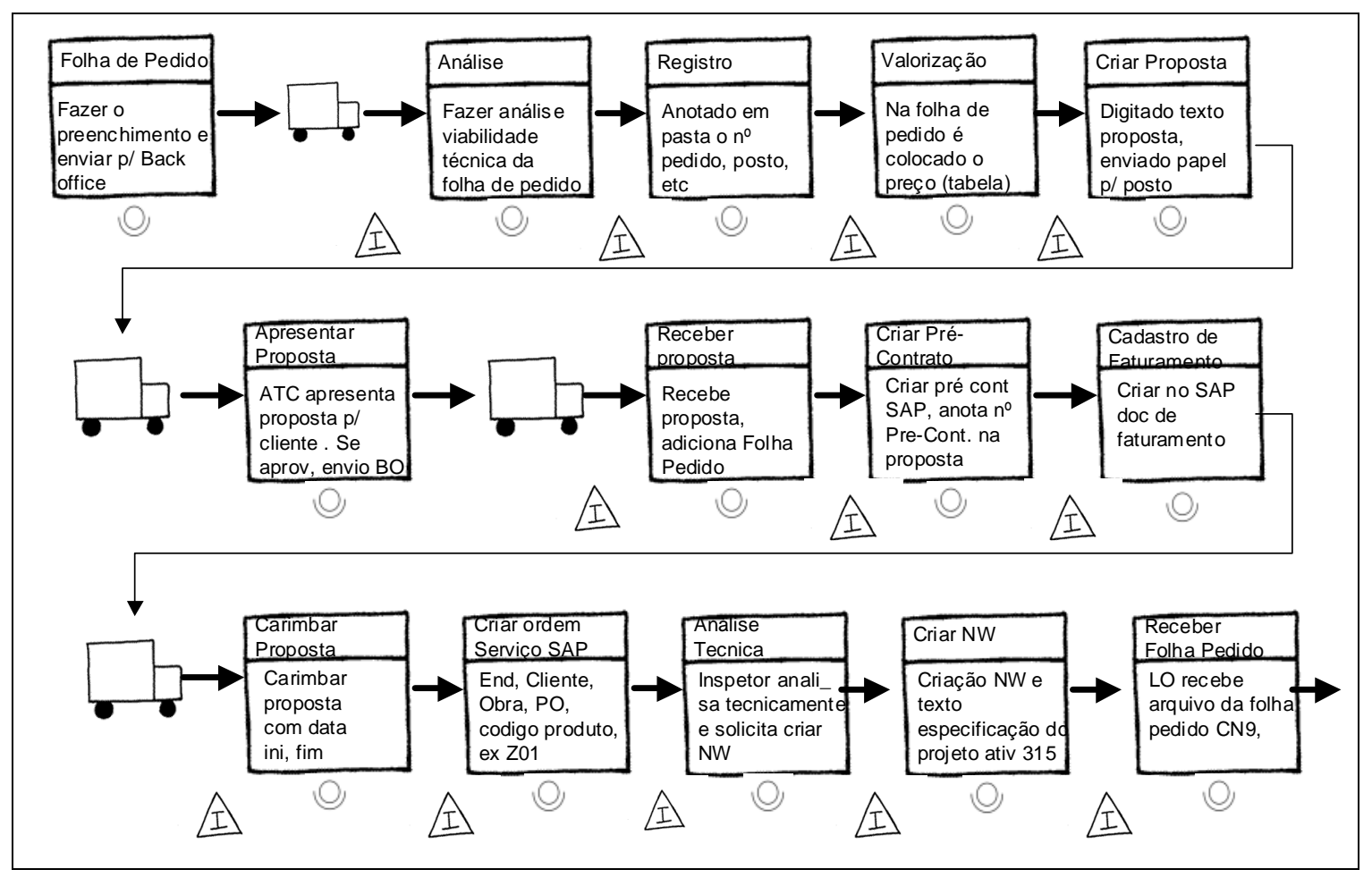

Figura 5 - Mapeamento do Processo de Venda

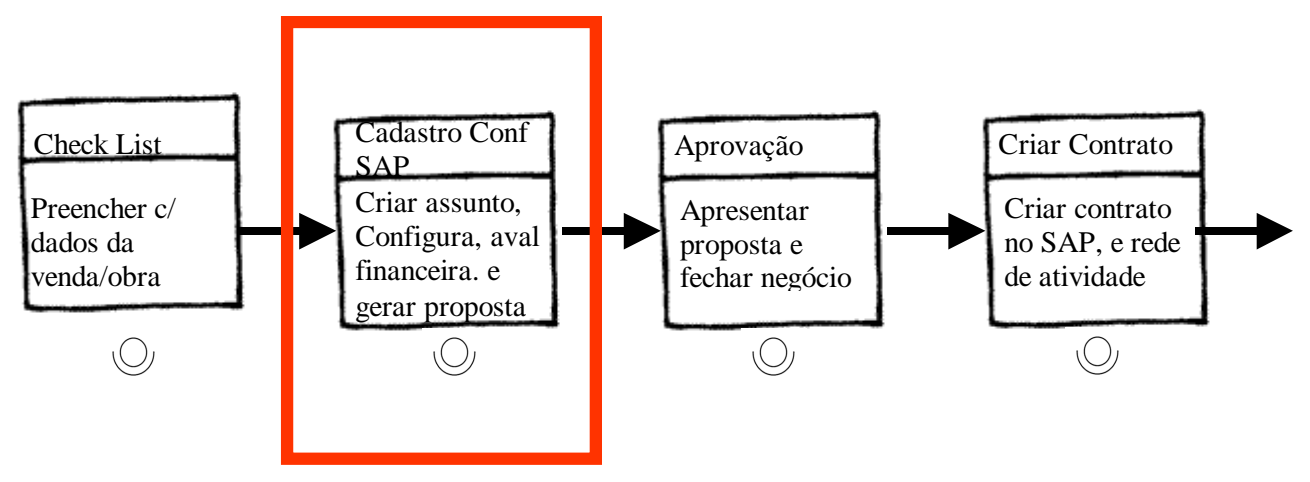

Figura 6 - Novo Processo de Venda

A entrega do projeto foi um sistema acessível pela intranet da empresa ou pelo ERP, onde todas as unidades do Brasil podem acessar, configurar os produtos, gerar custos e calcular os preços de acordo com a política de preços e descontos. Onde é selecionado automaticamente a rede de atividades adequada para cada aplicação de produto, bem como a geração do processo de cobrança, baseado nas condições de venda.

O projeto foi estruturado em partes para tornar administrável o trabalho a ser realizado. A estrutura ficou dividida em ações necessárias no produto para sua adaptação as várias configurações necessárias para atender uma ampla gama de necessidades de aplicação, ao desenvolvimento de uma interface homem-máquina que facilite a interação do usuário com o sistema de ERP (SAP), a criação de regras para aplicação do produto no ERP, vindo a restringir aplicações que não estão 
estruturadas, ao mapeamento do processo atual e redesenho do novo processo após a implementação do sistema, e a definição de métricas para medir a efetividade do processo bem como o treinamento e conscientização dos usuários e no novo processo de trabalho.

Um grande trabalho foi realizado no sistema de ERP que possui o módulo de configuração de variantes que teve regras desenvolvidas conforme as necessidades dos clientes e a estrutura de produto alterada, possibilitando configurar produtos de modo atender cerca de $80 \%$ das variações existentes no mercado.

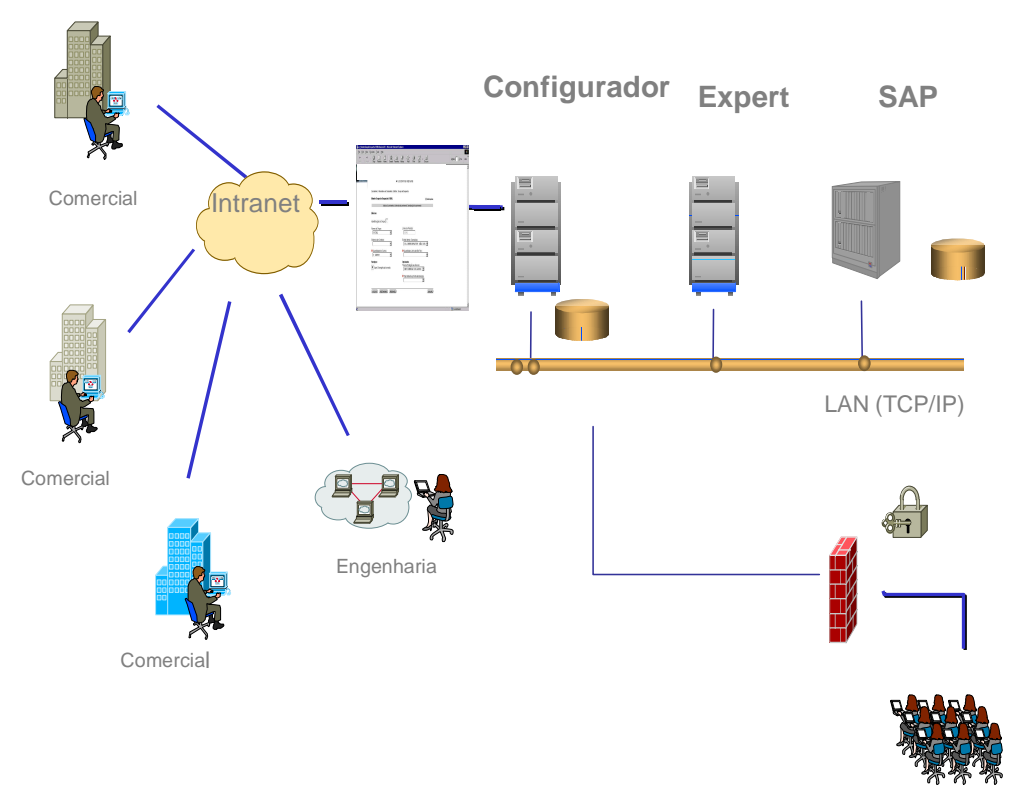

Figura 7 - Sistema Configurador de produtos web-enabled

O processo logístico também foi sujeito a melhorias e teve sua estrutura de trabalho melhorada através do redesenho das networks, que é a forma como o trabalho é distribuído na organização e entre os fornecedores. O treinamento e conscientização dos usuários foi parte fundamental na garantia do sucesso da implantação do novo sistema.

\subsection{Implementando a solução}

A implementação foi a fase onde o sistema foi introduzido em toda a empresa e o projeto, passou a fazer parte do processo operacional. O sistema foi colocado em produção no dia 01 de novembro de 2003, em todas as regiões. Foram treinadas mais de 100 pessoas que estão envolvidas de forma direta ou indireta no processo venda e pós venda de uma modernização.O novo sistema introduzido propicia ao usuários informar as características do elevador onde deseja-se modernizar, e através de regras um produto adequado é especificado. Neste ambiente web-enabled, o vendedor verifica as margens de lucro na venda e determina prazos de entrega do equipamento. Mediante a 
aprovação do consumidor final o vendedor autoriza a compra e a fabricação do produto, que é livre de erros de especificação.

\subsection{Discussão dos resultados}

O sistema trouxe significativa melhora no processo através da simplificação das etapas e da introdução de um sistema que possibilita o controle sistematizado do processo.

O novo processo propiciou uma redução no prazo de elaboração de uma proposta reduzindo o prazo para um terço do prazo original, além de automatizar as fases posteriores a assinatura do contrato que engloba a criação da network e a geração da ordem de venda de manufatura, na fábrica. Foram realizadas simulações na fábrica gerando-se ordens de produção e verificando sua consistência, o resultado foi satisfatório. As ordens de produção estavam conforme a configuração determinada no sistema, com isto infere-se que ao produzir o equipamento este estará conforme a especificação de venda e atendendo os requisitos de aplicação do produto.

Como o prazo entre a venda e entrega do produto é de 6 meses não será possível ainda, verificar o resultado na satisfação do cliente, pois a medição é realizada após 2 meses da instalação do produto, requerendo assim o prazo de nove meses a partir da data de implementação para obterse uma amostragem significativa das medições da satisfação do cliente.

A implementação do novo processo propicia um controle adequado sobre o custo, prazo e qualidade da venda. A diretoria financeira poderá apontar com precisão os custos da não qualidade do processo, facilitando assim a melhoria contínua das atividades da cadeia de valor.

\section{Conclusão}

Observou-se que as cadeias de suprimentos estão em constante evolução e que existe um crescente aumento da importância da informação na gestão das cadeias, independente da configuração que estas possam vir a assumir. O projeto das cadeias de suprimentos podem arranjar os parceiros no mesmo site de pordução ou em locais distantes a milhares de quilometros, mas verifica-se que a tomada de decisão e a distribuição da informação são os pontos de maior enfoque no futuro próximo.

O caso estudado mostra claramente a importância de uma informção de alta qualidade e disponibilizada no menor prazo de tempo para a cadeia de forma a propiciar visibilidade para os parceiros. Isto trouxe vários benefícios como a redução de prazo e redução de custos, que eram decorrentes da informação pobre no sistema. 
Mais uma vez os sistemas de tecnologia da informação ajudam no processo de disseminação da informação disponibilizando-a de forma rápida e precisa. Verificamos que o ERP está tornando-se limitado e que o mercado vem buscando alternativas de expansão dos domínios através de novos softwares adaptados para atender as condições específicas de cada negócio.

\section{ABSTRACT}

This text presents some concepts and tendencies about ERP and SCM, with the illustration of a real case, in a company of elevators, and the conclusion with the suggestion of a possible development, in a future well near to in the new needs you specify of the system ERP for service to the Supply Chain.

Key words: Supply chain, Cooperative Systems, ERP.

\section{Referências}

AKKERMANS, H. A.; BOGERD, P.; YUCESA, E.; WASSENHOVE, L. The impact of ERP on supply chain management: exploratory findings from European Delphi study. European Journal of Operational Research, p. 284$301,2003$.

ALWAYS on people. The Economist, jan. 2002.

BETH, S.; BURT, D.; COPACINO, W.; GOPAL, C.; LEE, H. L.; LYNCH, R. P.; MORRIS, S. Supply chain challenges: building relationships. Harvard Business Review, Jan. 2003.

CARVALHO, M. F. Cadeias cooperativas. 2001.

COPACINO, W. C.; HOWE, R. E. The logistics handbook. 1994. [Free Press].

RICE, J. B.; HOPPE, R. Three dimensions of supply network coordination: an introductory essay. MIT Center for Transportation Studies. Sept. 2002. 